\title{
Use of Continuous Physiological Monitor Data to Evaluate Doxapram Therapy in Preterm Infants
}

\author{
Jarinda A. Poppe ${ }^{a}$ Willem van Weteringen ${ }^{a, b}$ Swantje Völler ${ }^{a, c}$ \\ Sten P. Willemsen ${ }^{a}$ d Tom G. Goos ${ }^{a}$ Irwin K.M. Reiss ${ }^{a}$ Sinno H.P. Simons ${ }^{a}$ \\ a Department of Pediatrics, Division of Neonatology, Erasmus MC - Sophia Children's Hospital, University Medical \\ Center Rotterdam, Rotterdam, The Netherlands; bepartment of Pediatric Surgery, Erasmus MC - Sophia \\ Children's Hospital, University Medical Center Rotterdam, Rotterdam, The Netherlands; 'Systems Biomedicine \\ and Pharmacology, Leiden Academic Center for Drug Research, Leiden University, Leiden, The Netherlands; \\ dDepartment of Biostatistics, Erasmus MC, University Medical Center Rotterdam, Rotterdam, The Netherlands
}

\section{Keywords}

Pharmacotherapy · Apnea of prematurity · Monitoring ·

Personalized medicine

\begin{abstract}
Introduction: Evaluation of pharmacotherapy during intensive care treatment is commonly based on subjective, intermittent interpretations of physiological parameters. Realtime visualization and analysis may improve drug effect evaluation. We aimed to evaluate the effects of the respiratory stimulant doxapram objectively in preterm infants using continuous physiological parameters. Methods: In this longitudinal observational study, preterm infants who received doxapram therapy were eligible for inclusion. Physiological data $(1 \mathrm{~Hz})$ were used to assess respiration and to evaluate therapy effects. The oxygen saturation $\left(\mathrm{SpO}_{2}\right) /$ fraction of inspired oxygen $\left(\mathrm{FiO}_{2}\right)$ ratio and the area under the $89 \% \mathrm{SpO}_{2}$ curve (duration $\times$ saturation depth below target) were calculated as measures of hypoxemia. Regression analyses were performed in 1-h timeframes to discriminate therapy failure (intubation or death) from success (no intubation). Results: Monitor data of 61 patients with a median
\end{abstract}

(C) 2020 The Author(s)

Published by S. Karger AG, Basel

This article is licensed under the Creative Commons AttributionNonCommercial-NoDerivatives 4.0 International License (CC BYNC-ND) (http://www.karger.com/Services/OpenAccessLicense). Usage and distribution for commercial purposes as well as any distribution of modified material requires written permission. postmenstrual age (PMA) at doxapram initiation of 28.7 (IQR 27.6-30.0) weeks were available. The success rate of doxapram therapy was $56 \%$. Doxapram pharmacodynamics were reflected in an increased $\mathrm{SpO}_{2}$ and $\mathrm{SpO}_{2} / \mathrm{FiO}_{2}$ ratio as well as a decrease in episodes with saturations below target $\left(\mathrm{SpO}_{2}\right.$ $<89 \%$ ). The $\mathrm{SpO}_{2} / \mathrm{FiO}_{2}$ ratio, corrected for PMA and mechanical ventilation before therapy start, discriminated best between therapy failure and success (highest AUC ROC of 0.83 ). Conclusion: The use of continuous physiological monitor data enables objective and detailed interpretation of doxapram in preterm infants. The $\mathrm{SpO}_{2} / \mathrm{FiO}_{2}$ ratio is the best predictive parameter for therapy failure or success. Further implementation of real-time data analysis and treatment algorithms would provide new opportunities to treat newborns.

(c) 2020 The Author(s)

Published by S. Karger AG, Basel

\section{Introduction}

It is difficult to evaluate clinical effects of pharmacotherapy in preterm infants with continuously changing pharmacokinetics and pharmacodynamics. Doxapram is used off-label as a second-line treatment for persistent 
apnea of prematurity next to caffeine and noninvasive ventilation. It stimulates the respiratory drive through the brainstem respiratory center and the peripheral carotid and aortic chemoreceptors [1]. Doxapram is prescribed to avoid hypoxemic periods and to reduce the need for invasive mechanical ventilation (MV) [2]. Hypoxemic periods should be avoided as they are associated with an increased risk for late death or disability [3]. The occurrence of apneas is evaluated inconsistently based on the impression that nurses get from bedside alarm signals [4]. Additionally, only snapshots of bedside monitor data are used to assess a patient's condition. Clinical decisionmaking is thus commonly based on these subjective, snapshot interpretations, and a vast amount of potentially relevant information is discarded.

Storing, recalling, and analyses of per-second available physiological data may provide clinicians with information on the trends in a patient's condition. Real-time anal$y$ sis of this trend data can extract detailed information on important clinical changes and may predict therapy effect and outcome. The effectiveness of therapy may be increased and toxicity reduced. A small pilot study already showed that monitor data could potentially be used to evaluate doxapram therapy [5].

The aim of this study was to use doxapram therapy as a proof of principle to demonstrate the use of monitor data for the objective and continuous evaluation of respiration and drug effects in preterm infants.

\section{Materials and Methods}

In this longitudinal observational study, prospectively collected physiological data were analyzed. Eligible for inclusion were preterm infants with a birth weight $<1,500 \mathrm{~g}$ who received doxapram therapy between December 2013 and June 2017 at the neonatal intensive care unit (NICU) of Sophia Children's Hospital (Rotterdam, The Netherlands). Patients of the earlier conducted pilot study were part of this population. The local ethics review board granted a waiver from approval according to the Medical Research Involving Human Subjects Act (WMO) in the Netherlands (MEC-2018-1106).

Baseline characteristics were collected from the electronic medical records (HiX, Chipsoft, Amsterdam, The Netherlands). Ventilation mode and fraction of inspired oxygen $\left(\mathrm{FiO}_{2}\right)$ data were collected from the electronic patient data management system ( $\mathrm{Pi}$ cis Clinical Solutions, Inc., Wakefield, MA, USA). Physiological data - arterial oxygen saturation $\left(\mathrm{SpO}_{2}\right)$, respiratory rate $(\mathrm{RR})$, and heart rate (HR) - were continuously and automatically recorded $(1 \mathrm{~Hz})$ from bedside monitors (Dräger, Lübeck, Germany). The $\mathrm{SpO}_{2}$ was measured with pulse oximeters (Masimo Corporation, Irvine, CA, USA), and HR was derived from the electrocardiogram. Data were analyzed from 1 week before therapy start until 2 weeks after therapy start or therapy stop.

Continuous Evaluation of Doxapram

Therapy in Preterm Infants
Doxapram was administered if apnea of prematurity persisted under optimized caffeine treatment and noninvasive ventilation. The local protocol proposed a loading dose of $2.5 \mathrm{mg} / \mathrm{kg}$ in $15 \mathrm{~min}$, on indication of the attending physician, and a continuous maintenance dose of $2.0 \mathrm{mg} / \mathrm{kg} / \mathrm{h}$ by intravenous infusion or gastrointestinal administration. Clinicians assessed doxapram effectiveness by the occurrence of apneas and bradycardias, and alarm signals according to the local standards for $\mathrm{SpO}_{2}, \mathrm{RR}$, and HR. The alarms were set to indicate $\mathrm{SpO}_{2}$ below $89 \%$ or over $95 \%$, HR below 100 or over $200 \mathrm{bpm}$, and a respiratory pause of $20 \mathrm{~s}$ or longer. The maintenance dose was gradually reduced or stopped on clinical indication, or when MV was required. MV was not administered during doxapram therapy. The local criteria to start MV included persisting or severe apnea, increased oxygen needs or severe desaturations. Therapy success was defined as no MV requirement at therapy stop, and therapy failure was defined as death or MV requirement at therapy stop. A new doxapram course was defined as therapy restart at least $24 \mathrm{~h}$ after stop of the previous course.

Data were filtered for measurements that were marked as invalid by the patient monitoring system. Zero values were removed from the analysis as they also could indicate a disconnected sensor. The number and duration of episodes with saturations below an $\mathrm{SpO}_{2}$ limit of $89 \%$, the local lower alarm limit, were derived from the $\mathrm{SpO}_{2}$. The area under the $89 \% \mathrm{SpO}_{2}$ limit curve ( $\left.\mathrm{SpO}_{2} \mathrm{AUC}\right)$ was calculated by multiplying the time by the depth under the limit per second. All data were preprocessed using LabVIEW (National Instruments, Austin, TX, USA). The $\mathrm{SpO}_{2} / \mathrm{FiO}_{2}$ ratio was calculated per second where both $\mathrm{SpO}_{2}$ and $\mathrm{FiO}_{2}$ measurements were available.

The statistical analyses were performed using R software (version 3.5.3, Inc., Boston, MA, USA) and differences were considered significant at $p<0.05$. Baseline characteristics were analyzed using the Wilcoxon rank sum test, $\chi^{2}$ test, or Fisher's exact test. The sample was analyzed as a whole and in subgroups for therapy failure and success. The physiological data were described by median (IQR) per hour. Differences in physiological data between therapy failure and success at 12 and $1 \mathrm{~h}$ before, and 4 and $12 \mathrm{~h}$ after doxapram start were tested using the Wilcoxon rank sum test. Missing data points were assumed to be completely at random and were therefore excluded from the analysis.

Logistic regression models were fitted for each 1-h timeframe in the $48 \mathrm{~h}$ around therapy start with the $\mathrm{SpO}_{2} / \mathrm{FiO}_{2}$ ratio as independent variable. Only patients who had received doxapram for $24 \mathrm{~h}$ or more were included in the analysis. The same approach was applied with models including patient characteristics, the postmenstrual age (PMA) at therapy start, and MV in the $24 \mathrm{~h}$ before therapy start, and with models including both the $\mathrm{SpO}_{2} / \mathrm{FiO}_{2}$ ratio and the patient characteristics. The area under the receiver operating characteristic curve (AUC ROC) was calculated for each of the models.

Linear mixed-effects models were computed for each physiological parameter ( $\mathrm{R}$ package "nlme", version 3.1-137). We allowed for a nonlinear effect of time in the fixed-effects part, using natural splines concentrated around therapy start. In the randomeffect part we included random intercepts and splines. Differences within each of the parameters before and after therapy start were tested per 4 -h timeframe using the predicted data from the mixed models. The degree of change was visualized with the intensity of colors in matrix plots, significant differences were marked with a dot. 
Table 1. Baseline characteristics of the study population

\begin{tabular}{lccc}
\hline Characteristics & $\begin{array}{l}\text { Patients without } \\
\text { monitor data }(n=55)\end{array}$ & $\begin{array}{l}\text { Patients with } \\
\text { monitor data }(n=61)\end{array}$ & $p$ value* $^{*}$ \\
\hline Gestational age, weeks & $26.0(24.9-27.1)$ & $26.1(24.9-26.7)$ & 0.57 \\
Birth weight, g & $800(645-1,000)$ & $750(650-910)$ & 0.44 \\
Multiple birth (yes) & $19(35)$ & $17(28)$ & 0.57 \\
Male gender & $33(60)$ & $42(69)$ & 0.42 \\
Postnatal age ${ }^{\text {a }}$, days & $19.9(13.4-26.0)$ & $20.9(14.1-25.2)$ & 0.72 \\
Postmenstrual age ${ }^{\mathrm{a}}$, weeks & $29.0(27.5-30.8)$ & $66(51-97)$ & 0.49 \\
Admission period, days & $69(44-84)$ & $7(11)$ & 0.33 \\
Mortality (yes) & $8(15)$ & 0.78 \\
\hline
\end{tabular}

Data are presented as median (IQR) or as $n(\%) .{ }^{\text {a }}$ Age at doxapram initiation. ${ }^{*} p$ value from the Wilcoxon rank sum test, Fisher's exact test, and $\chi^{2}$ test.

Table 2. Patient characteristics classified in therapy success or therapy failure

\begin{tabular}{lccr}
\hline Characteristics & $\begin{array}{l}\text { Therapy success } \\
(n=65)\end{array}$ & $\begin{array}{l}\text { Therapy failure } \\
(n=52)\end{array}$ & $p$ value* $^{*}$ \\
\hline Gestational age, weeks & $26.3(25.4-27.3)$ & $25.3(24.5-26.3)$ & $<0.01$ \\
Birth weight, g & $820(650-985)$ & $730(648-868)$ & 0.10 \\
Multiple birth (yes) & $22(34)$ & $14(27)$ & 0.55 \\
Male gender & $37(57)$ & $38(73)$ & 0.11 \\
Postnatal age ${ }^{\text {a }}$ days & $21.9(16.8-29.9)$ & $16.6(12.7-22.8)$ & $<0.01$ \\
Postmenstrual age ${ }^{\mathrm{a}}$, weeks & $29.9(28.2-31.3)$ & $27.7(27.1-28.7)$ & $<0.01$ \\
Admission period, days & $58.5(45.2-78.5)$ & $76.0(55.5-92.9)$ & 0.03 \\
Mortality (yes) & $1(2)$ & $14(27)$ & $<0.01$ \\
Duration of therapy, days & $9.9(4.7-17.6)$ & $1.8(0.6-5.0)$ & $<0.01$ \\
Ventilation $\leq 24$ h before start (yes) & $16(25)$ & $30(58)$ & $<0.01$ \\
Number of doxapram courses & & & $<0.01$ \\
$\quad 1$ course & $53(82)$ & $25(48)$ & $15(29)$ \\
$\quad$ courses & $10(15)$ & $10(19)$ & $2(4)$ \\
$\quad 1(2)$ & $1(2)$ &
\end{tabular}

Data are presented as median (IQR) or as $n(\%)$. The patients are classified based on the therapy outcome of the first doxapram course. ${ }^{a}$ Age at doxapram initiation. * $p$ value from the Wilcoxon rank sum test, Fisher's exact test, and $\chi^{2}$ test.

\section{Results}

During the study period, 121 patients received doxapram therapy. We excluded 5 patients $(4 \%)$ due to the following reasons: therapy data missing $(n=3)$, transferred to another hospital $(n=1)$, birth weight $>1,500 \mathrm{~g}$ $(n=1)$. Monitor data were successfully collected for $61 / 116$ patients $(53 \%)$. No statistically significant differences were found between patients with and without available monitor data (Table 1). A total of $23,640 \mathrm{~h}(92 \%$; $82,776,281$ data points) of data were available for analysis.
The overall success rate was $56 \%$. The gestational age in patients with therapy success (26.3 [25.4-27.3] weeks) was higher than in patients with therapy failure (25.3 [24.5-26.3] weeks; $p<0.01)$. The postnatal age at initiation $(p<0.01)$ - and consequently also the PMA at initiation $(p<0.01)$ - was lower in patients with therapy failure (Table 2). Patients with therapy failure had a longer NICU stay $(p=0.02)$, were treated shorter $(p<0.01)$, and were more often on MV during the $24 \mathrm{~h}$ before start $(p<0.01)$. None of the patients received high-flow or MV at start of doxapram. 
Fig. 1. Trends of patients with available monitor data $(n=61)$ divided into groups with therapy failure and success in the arterial oxygen saturation $\left(\mathrm{SpO}_{2}\right)$, fraction of inspired oxygen $\left(\mathrm{FiO}_{2}\right), \mathrm{SpO}_{2} / \mathrm{FiO}_{2}$ ratio, number and duration of episodes with saturations below the $\mathrm{SpO}_{2}$ limit of $89 \%$, and the area under the curve below the $\mathrm{SpO}_{2}$ limit of $89 \%$ (a). Data were derived from $82,776,281$ unique measurements and visualized from 1 week before doxapram start until 2 weeks after doxapram start, and in a 48-h timeframe around doxapram start. The difference between the groups with therapy failure and success was tested at 12 and $1 \mathrm{~h}$ before doxapram, and 4 and $12 \mathrm{~h}$ after doxapram start. Significant differences are visualized in the 48-h timeframe graphs. Data obtained after therapy stop within the 2 weeks' study period were excluded from the analyses. The number of patients in the analyses, therefore, decreases during the study period. The total amount of patients in the analyses is presented per hour (b). Doxapram start is indicated by the vertical red line at time $=0$.
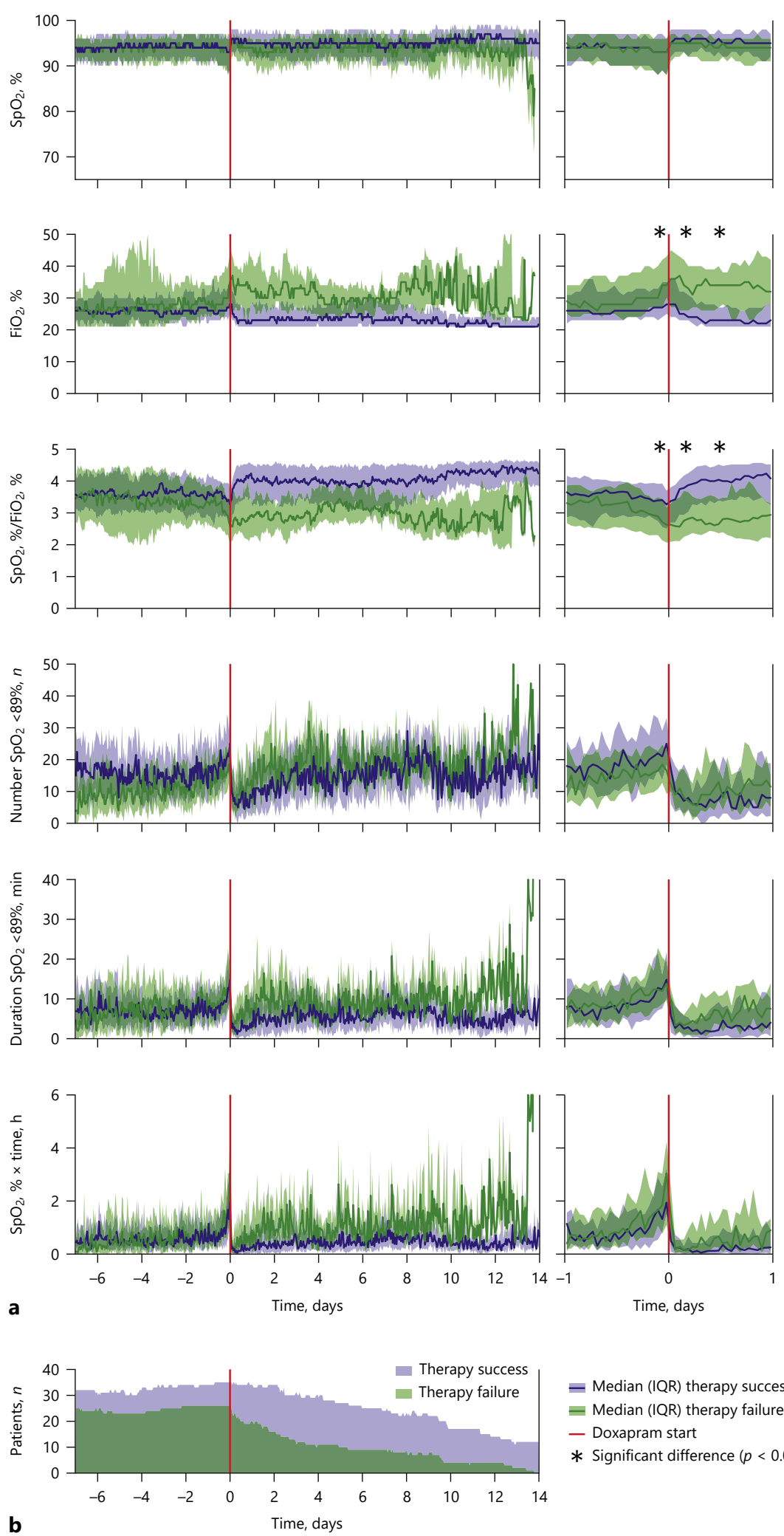

- Median (IQR) therapy success = Median (IQR) therapy failure

- Doxapram start

* Significant difference $(p<0.01)$ 


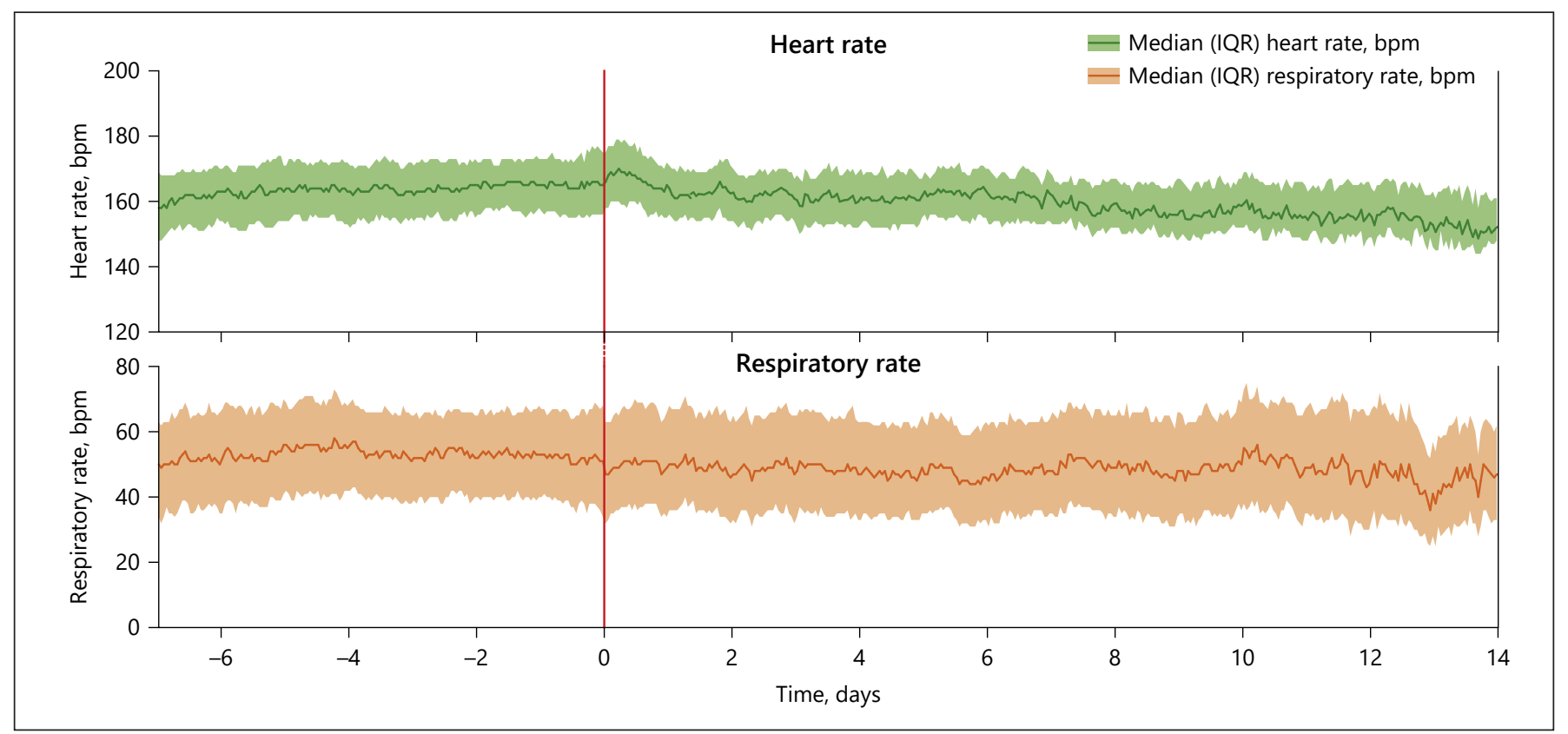

Fig. 2. The trends of the heart rate (bpm) and the respiratory rate (bpm) from 1 week before therapy start until 2 weeks after therapy start or therapy stop. Data obtained after therapy stop within the 2 weeks' study period were excluded from the analyses. The number of patients in the analyses can be found in Figure 1b. Doxapram start is indicated by the vertical red line at time $=0$.

The largest differences in the physiological data were seen in the first hours after therapy start (Fig. 1). Overall, the duration of episodes with saturations below target had decreased from $14(10-20)$ to $3(0-6) \mathrm{min} / \mathrm{h}$ (79\%), the number of episodes with saturations below target from $22(15-28)$ to $7(2-17)(69 \%)$, the AUC $\mathrm{SpO}_{2}$ from $2.0 \% / \mathrm{s}(1.3-3.5)$ to $0.2 \% / \mathrm{s}(0.0-0.4)(90 \%)$, and the $\mathrm{FiO}_{2}$ from $30 \%(26-40)$ to $27 \%(24-37)(10 \%)$ between $1 \mathrm{~h}$ before doxapram start and $4 \mathrm{~h}$ after start. The $\mathrm{SpO}_{2} / \mathrm{FiO}_{2}$ ratio had increased from 3.0 (2.2-3.6) to $3.5(2.5-4.1)(17 \%)$ and the $\mathrm{SpO}_{2}$ from $93 \%$ (88-96) to $95 \%$ (93-97) (2\%). The HR increased from 165 (156$175)$ to $168(160-177) \mathrm{bpm}(2 \%)$ and the RR decreased from 51 (34-68) to 49 (35-65) bpm (4\%; Fig. 2). The number of patients in the analysis was visualized per hour (Fig. 1b). At $1 \mathrm{~h}$ before and 4 and $12 \mathrm{~h}$ after doxapram start, the $\mathrm{FiO}_{2}$ and $\mathrm{SpO}_{2} / \mathrm{FiO}_{2}$ ratio differed significantly between patients with therapy failure and success $(p<0.01)$.

The results of the mixed-effects models are provided in online supplementary Figures S1 and S2 (for all online suppl. material, see www.karger.com/doi/10.1159/000509269). The predicted data of the mixed models showed similar trends in the physiological parameters when compared to the raw data.
The $\mathrm{SpO}_{2} / \mathrm{FiO}_{2}$ ratio trend in patients with therapy success differed from patients with therapy failure (Fig. 1a). The $\mathrm{SpO}_{2} / \mathrm{FiO}_{2}$ ratio had a steeper decrease before therapy start in patients with therapy failure than in patients with therapy success. The $\mathrm{SpO}_{2} / \mathrm{FiO}_{2}$ ratio increased after start in the group with therapy success and remained constant in the group with therapy failure. This trend in the $\mathrm{SpO}_{2} / \mathrm{FiO}_{2}$ ratio was still observed in both groups after 2 weeks (Fig. 1a).

Fifty-four patients received doxapram therapy for $24 \mathrm{~h}$ or more. Figure $3 \mathrm{~b}$ shows the discriminative ability of the $\mathrm{SpO}_{2} / \mathrm{FiO}_{2}$ ratio (Model 1), the PMA at doxapram administration and MV within $24 \mathrm{~h}$ before start (Model 2 ), and the combination of these 2 (Model 3 ). The ability to discriminate between therapy failure and success according to the hourly AUC ROC varied between 0.63 and 0.77 for Model 1, was 0.77 for Model 2, and varied between 0.77 and 0.83 for Model 3.

\section{Discussion}

This study used high-density physiological data to evaluate pharmacotherapy in preterm infants, and to predict respiratory outcome. The doxapram effect was reflected by 
Fig. 3. The discriminative ability of the oxygen saturation $\left(\mathrm{SpO}_{2}\right)$ /fraction of inspired oxygen $\left(\mathrm{FiO}_{2}\right)$ ratio for therapy outcome. Doxapram start is indicated by the vertical red line at time $=0$. Models included data based on patients with a therapy duration of $24 \mathrm{~h}$ or more. Patients with a therapy duration below $24 \mathrm{~h}(n=7)$ were excluded from these analyses. This graph shows the results of the hourly discriminative models for therapy success and failure, using the area under the ROC curve. The first groups of models included the $\mathrm{SpO}_{2} / \mathrm{FiO}_{2}$ ratio (Model 1). The second group included the patient characteristics: postmenstrual age at doxapram initiation and invasive ventilation during the $24 \mathrm{~h}$ before therapy start (Model 2). The third group included both the $\mathrm{SpO}_{2} / \mathrm{FiO}_{2}$ ratio and the patient characteristics (Model 3).

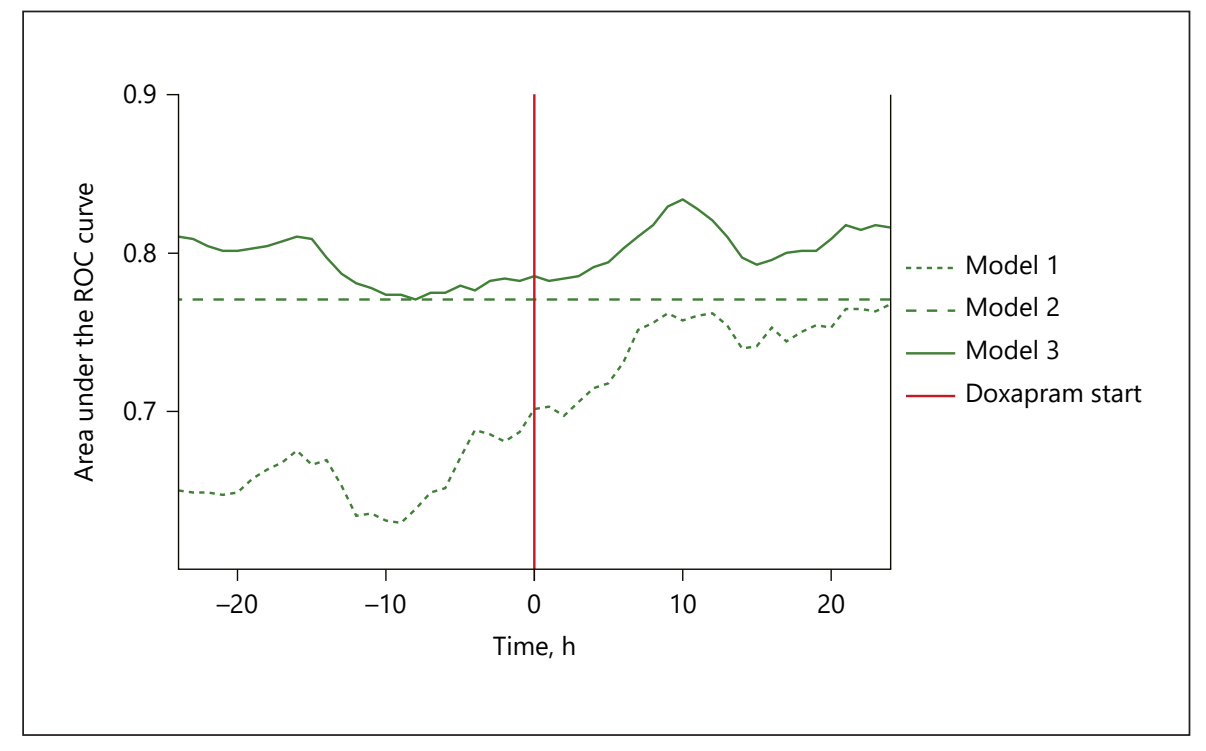

increased $\mathrm{SpO}_{2}$ and $\mathrm{SpO}_{2} / \mathrm{FiO}_{2}$ ratio levels, lower number and shorter duration of episodes with saturations below target, as well as lower $\mathrm{SpO}_{2} \mathrm{AUC}$ and $\mathrm{FiO}_{2}$ levels. The $\mathrm{SpO}_{2} /$ $\mathrm{FiO}_{2}$ ratio, corrected for PMA and MV during the $24 \mathrm{~h}$ before therapy start, was found to be discriminative for therapy outcome. These analyses of monitor data can provide an objective assessment of pharmacotherapy effects that is superior to the "snapshots" used in current clinical practice.

The success rate of doxapram is comparable to previous studies $[2,6]$. Doxapram can be effective for avoiding hypoxia and MV if administered to doxapram responders with the right indication. Trend visualization of physiological data could improve assessment of the respiratory status before starting therapy, avoiding unnecessary treatment. Real-time analysis of physiological data enables detection of early-onset patterns, probability assessments, and prediction of certain events over time. Applications of these analyses served to predict imminent critical deterioration [7] and cardiac arrest in the pediatric ICU [8]. HR characteristics have been used for early detection of lateonset neonatal sepsis, with lower mortality as a result [9].

In preterm infants, $\mathrm{SpO}_{2}$ needs to be strictly managed because of the risks of impaired neurodevelopment due to hypoxemia and retinopathy of prematurity due to hyperoxemia [3, 10-14]. Integration of $\mathrm{SpO}_{2}$ and $\mathrm{FiO}_{2}$ gives insight into the respiratory status of the patient as it accounts for the supplied oxygen level. The $\mathrm{SpO}_{2} / \mathrm{FiO}_{2}$ ratio was found to be a reliable marker for acute lung injury and acute respiratory distress syndrome in adults and children [15-17]. The $\mathrm{SpO}_{2} / \mathrm{FiO}_{2}$ ratio in preterm infants is inversely correlated with the gestational age at 36 weeks'
PMA, and is lower in infants with worse respiratory disease patterns [18]. In contrast to the oxygen saturation index (OSI; $\left[\mathrm{FiO}_{2} \times\right.$ mean airway pressure $\left.] / \mathrm{SpO}_{2}\right)$, the $\mathrm{SpO}_{2} / \mathrm{FiO}_{2}$ ratio does not include the mean airway pressure. The OSI has been validated only in invasively ventilated patients in the first days of life [19-21] and none of the patients in this study received MV around doxapram start or during doxapram therapy. Integration of noninvasive pressure support could further improve therapy, although it is known to be an unreliable measure for the mean airway pressure in the lungs.

Patients with therapy failure more often had MV during the $24 \mathrm{~h}$ before therapy start $(p<0.01)$. This could indicate extubation failure, resulting in higher need for respiratory support. MV was probably started in patients who had less capacity to overcome apneas. Apneas could result in hypoxic episodes more often, and the stimulatory effect of doxapram could be absent during hypoxia [22]. Although speculative, this could explain why doxapram was less beneficial in patients who needed MV just before therapy start. In ventilated patients, the $\mathrm{SpO}_{2} / \mathrm{FiO}_{2}$ ratio can be equal to that in noninvasively or nonventilated patients, thus concealing possibly worse hypoxemic events. The $\mathrm{SpO}_{2} / \mathrm{FiO}_{2}$ ratio in invasively ventilated patients is likely an overestimation of the respiratory status. This could explain the increasing discriminative ability before therapy start when patient characteristics, including MV, were added to the model.

The most important contribution of this study is the incentive for bedside trend visualization and more con- 
tinuous and objective pharmacotherapeutic evaluation in respiratory unstable patients. The $\mathrm{SpO}_{2} / \mathrm{FiO}_{2}$ ratio and episodes with a saturation below target can provide highly relevant information to clinicians on indication and individual dose evaluation of pharmacotherapy. We determined an acceptable to excellent discriminative ability for therapy outcome using physiological data [23]. The next step would be to calculate individualized risk indexes to predict therapy failure. Determination of cutoff values indicative of clinical conditions can validate parameters for objective decision-making. Such use of physiological data could be applied to other neonatal treatments, such as evaluation of caffeine effectiveness and safety [24], antibiotic dosing [25], and measurement of respiratory depression after morphine administration [26].

Several limitations of the study need to be addressed. First, the population at the NICU is heterogeneous, making it difficult to define a valid control group. In this study, each patient serves as his own control. The breathing center, however, matures over time, causing less apnea and related desaturations over time. We therefore corrected for the PMA at doxapram start in the discrimination of therapy outcome. Second, therapy failure was defined as MV requirement. The decision to start MV was made by the clinical team as consensus about respiratory insufficiency, and objective intubation criteria are lacking in neonatal treatment. Scores to assess the apnea severity have been suggested before but have not been validated in clinical practice [27]. This is a limitation, although it reflects the current standard of care.

In the near future, patient monitoring will inevitably contain real-time algorithms derived from continuous physiological data. Clinicians will be provided with information that in its raw form is too complex to be interpreted by the human brain. Translation of our findings to the bedside enables objective effect monitoring over time, and objective determination of respiratory failure. Objective and continuous monitoring enhances clinical deci- sion-making, and therapy can be adjusted based on the alterations of a patient's condition. This individualized treatment strategy is likely to lead to higher drug effectivity and fewer side effects compared to current clinical practice.

\section{Acknowledgement}

The authors thank Dr. J. Hagoort from the Department of Pediatric Surgery at Erasmus MC for carefully reading and editing the text.

\section{Statement of Ethics}

The local Ethics Review Board granted a waiver from approval for this study, according to the Medical Research Involving Human Subjects Act (WMO) in the Netherlands (MEC-2018-1106).

\section{Conflict of Interest Statement}

The authors have no conflicts of interest to declare.

\section{Funding Sources}

This study was funded by the Sophia Foundation (grant number: S18-27) and Stichting Coolsingel (grant number: 516).

\section{Author Contributions}

J.A.P., W.W., and S.H.P.S. conceived the study. J.A.P., W.W., S.H.P.S., S.V., T.G.G., and I.K.M.R. participated in the study design. J.A.P. and W.W. collected and processed the data, and J.A.P. and S.P.W. performed the data analyses. W.W. and S.H.P.S. cowrote the manuscript, and all authors revised the manuscript for intellectual content. All authors gave their final approval for publication of the manuscript and agreed to be accountable for all aspects of the work.

\section{References}

1 Yost CS. A new look at the respiratory stimulant doxapram. CNS Drug Rev. 2006;12(3-4): 236-49.

2 Flint R, Halbmeijer N, Meesters N, van Rosmalen J, Reiss I, van Dijk M, et al. Retrospective study shows that doxapram therapy avoided the need for endotracheal intubation in most premature neonates. Acta Paediatr. 2017 May; 106(5):733-9.

3 Poets CF, Roberts RS, Schmidt B, Whyte RK, Asztalos EV, Bader D, et al.; Canadian Oxygen Trial Investigators. Association Between
Intermittent Hypoxemia or Bradycardia and Late Death or Disability in Extremely Preterm Infants. JAMA. 2015 Aug;314(6):595-603.

4 Brockmann PE, Wiechers C, Pantalitschka T, Diebold J, Vagedes J, Poets CF. Under-recognition of alarms in a neonatal intensive care unit. Arch Dis Child Fetal Neonatal Ed. 2013 Nov;98(6):F524-7.

5 Flint RB, Weteringen WV, Voller S, Poppe JA, Koch BC, de Groot R, et al.; Dino Research Group. Big data analyses for continuous evaluation of pharmacotherapy: A proof of prin- ciple with doxapram in preterm infants. Curr Pharm Des. 2017;23(38):5919-27.

6 Prins SA, Pans SJ, van Weissenbruch MM, Walther FJ, Simons SH. Doxapram use for apnoea of prematurity in neonatal intensive care. Int J Pediatr. 2013;2013:251047.

7 Rusin CG, Acosta SI, Shekerdemian LS, Vu EL, Bavare AC, Myers RB, et al. Prediction of imminent, severe deterioration of children with parallel circulations using real-time processing of physiologic data. J Thorac Cardiovasc Surg. 2016 Jul;152(1):171-7. 
8 Kennedy CE, Aoki N, Mariscalco M, Turley JP. Using Time Series Analysis to Predict Cardiac Arrest in a PICU. Pediatr Crit Care Med. 2015 Nov; 16(9):e332-9.

9 Moorman JR, Carlo WA, Kattwinkel J, Schelonka RL, Porcelli PJ, Navarrete CT, et al. Mortality reduction by heart rate characteristic monitoring in very low birth weight neonates: a randomized trial. J Pediatr. 2011 Dec; 159(6):900-6.e1.

10 Schmidt B, Whyte RK, Asztalos EV, Moddemann D, Poets C, Rabi Y, et al.; Canadian Oxygen Trial (COT) Group. Effects of targeting higher vs lower arterial oxygen saturations on death or disability in extremely preterm infants: a randomized clinical trial. JAMA. 2013 May;309(20):2111-20.

11 Stenson BJ, Tarnow-Mordi WO, Darlow BA Simes J, Juszczak E, Askie L, et al.; BOOST II New Zealand Collaborative Group. Oxygen saturation and outcomes in preterm infants. N Engl J Med. 2013 May;368(22):2094-104.

12 Carlo WA, Finer NN, Walsh MC, Rich W, Gantz MG, Laptook AR, et al.; SUPPORT Study Group of the Eunice Kennedy Shriver NICHD Neonatal Research Network. Target ranges of oxygen saturation in extremely preterm infants. N Engl J Med. 2010 May; 362(21):1959-69.

13 Tarnow-Mordi W, Stenson B, Kirby A, Juszczak E, Donoghoe M, Deshpande S, et al.; BOOST-II Australia and United Kingdom Collaborative Groups. Outcomes of Two Trials of Oxygen-Saturation Targets in Preterm Infants. N Engl J Med. 2016 Feb;374(8):74960.
14 Vaucher YE, Peralta-Carcelen M, Finer NN, Carlo WA, Gantz MG, Walsh MC, et al.; SUPPORT Study Group of the Eunice Kennedy Shriver NICHD Neonatal Research Network. Neurodevelopmental outcomes in the early CPAP and pulse oximetry trial. N Engl J Med. 2012 Dec;367(26):2495-504.

15 Bilan N, Dastranji A, Ghalehgolab Behbahani A. Comparison of the spo2/fio2 ratio and the pao2/fio2 ratio in patients with acute lung injury or acute respiratory distress syndrome. J Cardiovasc Thorac Res. 2015;7(1):28-31.

16 Chen WL, Lin WT, Kung SC, Lai CC, Chao CM. The Value of Oxygenation Saturation Index in Predicting the Outcomes of Patients with Acute Respiratory Distress Syndrome. J Clin Med. 2018 Aug;7(8):E205.

17 Khemani RG, Thomas NJ, Venkatachalam V, Scimeme JP, Berutti T, Schneider JB, et al.; Pediatric Acute Lung Injury and Sepsis Network Investigators (PALISI). Comparison of SpO2 to $\mathrm{PaO} 2$ based markers of lung disease severity for children with acute lung injury. Crit Care Med. 2012 Apr;40(4):1309-16.

18 Nobile S, Marchionni P, Gidiucci C, Correani A, Palazzi ML, Spagnoli C, et al.; Marche Neonatal Network. Oxygen saturation/FIO2 ratio at 36 weeks' PMA in 1005 preterm infants: effect of gestational age and early respiratory disease patterns. Pediatr Pulmonol. 2019 May;54(5):637-43.

19 Doreswamy SM, Chakkarapani AA, Murthy P. Oxygen Saturation Index, A Noninvasive Tool for Monitoring Hypoxemic Respiratory Failure in Newborns. Indian Pediatr. 2016 May;53(5):432-3.
20 Muniraman HK, Song AY, Ramanathan R, Fletcher KL, Kibe R, Ding L, et al. Evaluation of Oxygen Saturation Index Compared with Oxygenation Index in Neonates with Hypoxemic Respiratory Failure. JAMA Netw Open. 2019 Mar;2(3):e191179.

21 Rawat M, Chandrasekharan PK, Williams A, Gugino S, Koenigsknecht C, Swartz D, et al. Oxygen saturation index and severity of hypoxic respiratory failure. Neonatology. 2015; 107(3):161-6.

22 Kruszynski S, Stanaitis K, Brandes J, Poets CF, Koch H. Doxapram stimulates respiratory activity through distinct activation of neurons in the nucleus hypoglossus and the pre-Bötzinger complex. J Neurophysiol. 2019 Apr; 121(4):1102-10.

23 Hosmer DW Jr, Lemeshow S, Sturdivant RX. Applied Logistic Regression, 3rd Edition. Hoboken, NJ: John Wiley \& Sons; 2013. p. 173-82.

24 Henderson-Smart DJ, Steer P. Methylxanthine treatment for apnea in preterm infants. Cochrane Database Syst Rev. 2001;(3):CD000140.

25 Elbers PW, Girbes A, Malbrain ML, Bosman R. Right dose, right now: using big data to optimize antibiotic dosing in the critically ill. Anaesthesiol Intensive Ther. 2015;47(5):457-63.

26 Hartley C, Moultrie F, Hoskin A, Green G, Monk V, Bell JL, et al. Analgesic efficacy and safety of morphine in the Procedural Pain in Premature Infants (Poppi) study: randomised placebo-controlled trial. Lancet. 2018 Dec; 392(10164):2595-605

27 Poets CF. Interventions for apnoea of prematurity: a personal view. Acta Paediatr. 2010 Feb;99(2):172-7. 